\section{PUBLIC PROPERTY AND ITS STATE FORM: CONTRADICTIONS AND POTENTIAL OF THE USSR}

\section{A.V. Buzgalin}

DOI: $10.33293 / 1609-1442-2021-4(95)-122-127$

Alexander V. Buzgalin, Department of Political Economy of the Faculty of Economics of Lomonosov Moscow State University; Center for Modern Marxist Studies of the Faculty of Philosophy of Lomonosov Moscow State University, Moscow, Russia; buzgalin@mail.ru. ORCID 0000-0003-3923-8385

Acknowledgments. The research was funded by RFBR, project number 21-010-43007\21.

The article shows that in the USSR, the development of associated social creativity (including such a phenomenon as "enthusiasm"), based on public property, was opposite to the opinions of most economists one of the important sources of development of this economic system. At the same time, the opposite content was hidden behind the form of public property in the USSR - the alienation of workers from the functions of management and appropriation of public wealth due to the bureaucratization of state property, which was the main brake on the development of the economy in which these property relations dominated. The analysis of this contradiction shows that public property most fully realizes its potential either as a state property (in such extreme conditions as wars, global catastrophes, etc.), or to the extent it is based on associated social creativity. The potential of public disposal and appropriation based on social creativity is especially great in the field of production of public goods (education, health care, art), where public ownership of the results of creative work can take the form of "everyone's ownership of everything", which makes it possible to remove the restrictions of intellectual private property.

Keywords: USSR, public property, social creativity, public goods, state, bureaucracy.

JEL classification: B51, P26, H82, D73, H41.

Manuscript received 29.09.2021

\section{СОВЕТСКОЕ ПЛАНИРОВАНИЕ: ЧТО И ПОЧЕМУ АКТУАЛЬНО В XXI в. ${ }^{1}$}

\author{
А.И. Колганов
}

DOI: $10.33293 / 1609-1442-2021-4(95)-127-132$

Планирование получило широкое распространение в странах с различными социально-экономическими системами. При этом оценки результатов использования плановых методов, как и сами эти плановые методы, отмечают существенные различия. Они зависят как от особенностей социально-экономических систем, в которых применялось планирование, так и от задач, которое оно решало. Для исследования этих зависимостей полезно обратиться к опыту планирования в СССР, который демонстрирует разные варианты использования плановых методов. В годы новой экономической политики планирование функционировало в условиях широкого развития рыночных и капиталистических отношений. Поэтому методы планирования были адаптированы к условиям рынка. Само планирование было преимущественно индикативным, а достижение плановых результатов строилось путем воздействия на экономические интересы экономических субъектов. Поэтому можно обнаружить значительное сходство в модели советского планирования в годы новой экономической политики и тех плановых методов, которые применялись в послевоенный период в Европе, Японии, а затем и в новых индустриальных странах. Модель директивного планирования, получившая

(с) Колганов А.И., 2021 г.

Колганов Андрей Иванович, доктор экономических наук, профессор, заведующий лабораторией сравнительного исследования экономических систем, Экономический факультет МГУ имени М.В. Ломоносова; главный научный сотрудник, Институт экономики РАН, Москва, Россия; onaglo@mail.ru. ORCID 0000-0003-2223-7538

1 Исследование выполнено при финансовой поддержке РФФИ в рамках научного проекта № 21-010-43007\21. 
развитие в СССР в 1930-е гг,, обеспечивала определенные преимущества в развитии экономики (мобилизация и концентрация значительных масс ресурсов для глубоких структурных сдвигов в экономике, осуществление крупных научно-технических и социальных проектов), но была также обременена серьезными противоречиями. Советская модель директивного планирования не имела эффективных институтов, выражавших экономические интересы предприятий и их коллективов, не создавала стимулов для технического перевооружения действовавших предприятий и привела в конечном итоге к преобладанию интересов верхушки государственных ведомств. Для предотвращения развития подобных противоречий, однобокого отражения интересов узких социальных групп плановая система должна строиться на демократических основаниях.

Ключевые слова: планирование, директивное планирование, индикативное планирование, новая экономическая политика, рыночная экономика, структурные сдвиги.

Классификачия JEL: O20, P11, P21.

\section{ВВЕДЕНИЕ}

В рыночной экономике, где производственные решения формируются как реакции на меняющиеся сигналы рыночной среды, планирование является неотъемлемым элементом. И действительно, планирование на национальном уровне - явление сравнительно недавнее, но уже прочно вошедшее в экономическую практику. Национальные планы, проекты, программы - как их ни называть призваны продвигать национальную экономику или ее значимые секторы к определенным целям.

Тем не менее отношение к планированию складывалось и складывается неоднозначно. Исторический опыт национального планирования знает и несомненные достижения, и существенные негативные последствия. Тем важнее разобраться, что из исторического опыта планирования может быть актуальным для нас сейчас, в начале XXI в.

\section{ЗАДАЧИ И МЕТОДИКА ИССЛЕДОВАНИЯ}

Для оценки возможности применить исторический опыт планирования в современных условиях обратимся к собственному советскому историческому опыту, сравним подходы к планированию и его результаты на разных этапах развития нашей страны. Кроме того, следует сопоставить применявшиеся в нашей стране методы планирования и стоящие перед ним цели с целями и методами планирования в других странах.

Прежде всего предстоит определить, какие проблемы решались при опоре на плановые методы руководства экономикой. Далее необходимо установить, в чьих интересах осуществлялось планирование, кто влиял на принимаемые плановые решения. Кроме того, следует изучить, в какой экономической системе осуществлялось планирование.

\section{РЕЗУЛЬТАТЫ И ИХ ОБСУЖДЕНИЕ}

Советская модель плановой системы менялась в зависимости от социально-экономических условий, в которых она развивалась. Однако, несмотря на различия, подчас весьма существенные, в этой модели можно найти и неизменные черты, остававшиеся инвариантными на любом этапе.

В советской модели планированию была предназначена роль, не вспомогательная по отношению к рыночным отношениям (как это было в большинстве других моделей общенационального планирования), а роль главного механизма, координирующего экономическую активность. Этот факт нашел отражение в известной дискуссии в СССР между сторонниками генетического и телеологического подходов к планированию в 1920-е гг. Сторонники генетического подхода во многом обоснованно критиковали своих оппонентов, не без осно- 
ваний опасаясь, что под вывеской телеологического подхода может скрываться стремление произвольно принимать экономические решения (Кондратьев, 1927, с. 33; Базаров, 1924 , с. 8). Можно заметить, что в середине 1920-х годов эта критика во многом перекликалась даже с позицией высших партийных инстанций (Постановление, 1927/1984, c. 275-276). Однако сторонники телеологического подхода тогда правильно подметили, что советское планирование было призвано менять развитие экономики в направлениях, определяемых по критериям, отличным от рыночных (Струмилин, 1958, с. 312).

Стоит отметить, что такая плановая модель, которая могла функционировать независимо от рыночных соображений, возникла не вдруг и не была продуктом чистого произвола. Эта модель выращивалась постепенно, начиная от простейших форм.

Первые попытки общенационального планирования в Советской России предпринимаются в 1920 г. с составления и принятия плана ГОЭЛРО, имевшего стратегический характер. Практически сразу его реализация была поставлена в условия повсеместного распространения рыночных, а отчасти и капиталистических отношений. Поэтому нэповская модель планирования имела переходный характер, являлась ступенькой к плану как господствующей форме экономической координации. Будучи встроенной в рыночно-капиталистическую (хотя бы отчасти) систему, она оказалась действующим прообразом дальнейшего развития плановой деятельности в экономиках, относящихся к рыночно-капиталистическому типу.

Планирование в СССР в этот период имело индикативный характер - обязательных плановых заданий от вышестоящих органов управления экономикой не поступало, хозрасчетные тресты должны были сами составлять годичные планы работы, которые утверждали вышестоящие органы (Авдаков, Бородин, 1973, с. 73-75). Для нэповской плановой модели было характерно использование тех методов, которые впоследствии широко применялись и применяются при планиро- вании и программировании экономики в развитых и новых индустриальных странах. Эти методы включают государственные закупки, прямые бюджетные инвестиции и бюджетные субсидии, налоговые и кредитные льготы, таможенные преференции, государственную научно-техническую помощь. Все эти инструменты воздействия на экономическое развитие должны были обеспечить достижение показателей общегосударственного плана.

Основные усилия советской модели плановой системы были ориентированы на осуществление глубоких структурных сдвигов в экономике: форсированная индустриализация, механизация на этой основе сельского хозяйства, резкое увеличение удельного веса промышленности и создание новых высокотехнологичных отраслей. Эти процессы подкреплялись подлинной культурной революцией.

Решение именно такого рода задач роднит советскую плановую модель с плановыми моделями в послевоенной Европе (Rosser J., Rosser M., 2004; Estrin, Holmes, 1983), Японии (Moriguchi, 1980; Хлынов, 2000) и позднее в новых индустриальных странах (Kuznets, 1990; Balassa, 1990). Все они обеспечивали быстрые и глубокие структурные сдвиги.

Разумеется, во всех развитых странах рыночные отношения остаются господствующими, хотя в экономическую систему уже давно встроены институты государственного регулирования рынка. Но экономические модели, где применяются те или иные формы общегосударственного планирования, характеризуются значительно более глубоким воздействием нерыночных институтов на функционирование рыночных отношений.

В СССР, однако, в развитии плановой экономики был сделан дальнейший шаг переход от преимущественно индикативных планов экономического развития к общенацииональной системе директивного планирования. Этот переход создал для развития экономики новые возможности, но и углубил имевшиеся противоречия плановой системы.

Общегосударственный директивный план строился на системе балансовых рас- 
четов, позволявших обеспечить пропорциональное развитие различных отраслей народного хозяйства. Множество директивных показателей производства в натуральном выражении придавало планам чрезмерную жесткость (поскольку их пересмотр был возможен лишь для следующего планового периода). Составной частью плана являлось распределение государственных капитальных вложений, определявшее сдвиги в структуре производства и распределение значительной части промежуточной и конечной продукции.

План нацеливал производство на достижение некоторых общегосударственных целей. Но отношения, определявшие как формулировку этих целей, так и выбор средств их достижения, таили в себе существенные противоречия, зародившиеся еще в нэповской модели планирования и значительно углубившиеся при переходе к директивному планированию.

Несовпадение общегосударственных и локальных интересов при формировании плана в той или иной степени неизбежно, а нахождение правильного баланса между ними позволяло превращать стремление к удовлетворению локальных интересов в инструмент обеспечения общегосударственных. В противном случае либо подавлялись локальные интересы, либо размывались общегосударственные.

Нэповская модель включала институты, призванные выражать локальные интересы в формах, соответствующих рыночным условиям хозяйствования (например, согласование структуры выпуска продукции и цен между синдикатами и органами потребительской кооперации) (Гуревич, 1927, с. 226; Малафеев, 1964, с. 80). Переход к директивному планированию ликвидировал эти институты, но локальные интересы от этого не исчезли, пробивая себе дорогу в латентных, а потому искаженных формах.

Другие противоречия были связаны с тем, интересы каких социальных групп и классов будут решающими при принятии плановых решений. До середины 1930-х годов существовали, развивались и возникали социально-экономические институты, в той или иной степени отражавшие интересы трудящего большинства населения хотя бы на локальном уровне (профсоюзы, производственные совещания, хозрасчетные бригады, встречное планирование...) (Рабочий класс, 1968, с. 218219; Лебедева, Шкаратан, 1966, с. 108-112). Но с середины 1930-х годов даже те из них, которые сохранили свое существование, уже перестали быть каналом выражения интересов рабочих. В то же время интересы государственного аппарата, и в особенности его верхушки, стали приобретать самодовлеющее значение.

В конечном итоге планирование превратилось в продукт борьбы и согласования интересов прежде всего руководителей государственных ведомств. В результате общенациональное планирование, обеспечивавшее вплоть до середины 1960-х годов глубокие структурные сдвиги в экономике и реализацию крупных научно-технических программ, превратилось в инструмент инерционного движения «от достигнутого», сползания к бюрократической стабильности и застою, накоплению экономических диспропорций.

\section{ЗАКЛЮЧЕНИЕ}

Имеющийся исторический опыт позволяет извлечь из него как богатый арсенал методов планирования, который может быть использован применительно к различным экономическим системам, так и ряд уроков.

Следует понимать, что планирование особая система отношений и соответствующих институтов, которые должны быть правильным образом модифицированы, чтобы вписаться в существующие экономические модели. Планирование, как и любые другие экономические отношения и институты, вырастает на объективной почве, выращивается путем накопления социального опыта, начиная со своих простейших форм и предпосылок.

Для планирования должны быть обеспечены высокий уровень прозрачности эко- 
номики и общественный контроль, без чего невозможны достоверность информации и правильное отражение различных экономических интересов.

Необходим постоянный поиск подходящих для данных конкретных условий форм сочетания неизбежно противоречащих друг другу плановых, рыночно-стоимостных и капиталистических институтов и критериев принятия экономических решений.

Успешность применения плановых методов в долгосрочной перспективе во многом зависит от степени демократизма социально-экономических институтов планирования и демократизма применяемых процедур подготовки и контроля осуществления планов (Hahnel, 2012; Gomez-Ramirez, 2014). Использование планирования для обеспечения интересов ограниченных групп в конечном счете будет вести к накоплению социально-экономических напряжений.

Эти уроки, которые мы можем извлечь из исторического опыта планирования, позволяют рассчитывать на успешность развития и применения плановых методов в XXI в., в том числе и в нашей стране, особенно если учесть глубину и сложность экономических проблем, которые стоят сегодня перед Россией.

\section{Список литературы / References}

Авдаков Ю.К., Бородин В.В. (1973). Производственные объединения и их роль в организации управления советской промышленностью (1917-1932 гг.). М.: Изд-во МГУ. [Avdakov Yu.K., Borodin V.V. (1973). Production associations and their role in the organization of management of Soviet industry (1917-1932). Moscow: Publishing House of Moscow State University (in Russian).]

Базаров В. (1924). К методологии перспективного планирования, Москва: Госплан. [Bazarov V. (1924). On the methodology of long-term planning, Moscow: Gosplan (in Russian).]
Гуревич Х.О. (1927). Генеральные договоры и взаимоотношения госпромышленности с потребкооперацией // Социалистическое хозяйство. № 5-6. [Gurevich Kh.O. (1927). General contracts and relations of the state industry with consumer cooperation. Socialist Economy, no. 5-6 (in Russian).]

Кондратьев Н.Д. (1927). План и предвидение // Пути сельского хозяйства. № 2. [Kondrat'ev N.D. (1927). Plan and foresight. Ways of agriculture, no. 2 (in Russian).]

Лебедева Н.Б., Шкаратан О.И. (1966). Очерки истории социалистического соревнования. Л.: Лениздат [Lebedeva N.B., Shkaratan O.I. (1966). Essays on the history of socialist competition. Leningrad: Lenizdat (in Russian).]

Малафеев А.Н. (1964). История ценообразования в CCCP (1917-1963 гг.). М.: Мысль. [Malafeev A.N. (1964). The history of pricing in the USSR (1917-1963). Moscow: Mysl (in Russian).]

Постановление (1984). Постановление XV съезда ВКП(б) «О директивах по составлению пятилетнего плана народного хозяйства». 19 декабря 1927 г. // КПСС в резолюциях и решениях съездов, конференций и пленумов ЦК (18981986). 9-е изд., доп. и испр. Т. 4: 1926-1929, Москва. [Resolution (1984). Resolution of the XV Congress of the VCP(b) "On directives for drawing up a five-year plan of the national economy”. December 19, 1927. The CPSU in resolutions and decisions of congresses, conferences and plenums of the Central Committee (18981986). 9th ed., add. and corr. Vol. 4: 1926-1929. Moscow: Politizdat (in Russian).]

Рабочий класс (1968). Рабочий класс в управлении государством (1926-1937 гг.). М.: Мысль. [Тhe Working Class (1968). The Working Class in state administration (1926-1937). Moscow: Mysl (in Russian).]

Струмилин С.Г. (1958). На плановом фронте. 1920 1930 гг. М.: Госполитиздат. [Strumilin S.G. (1958). On the planning front. 1920-1930. Moscow: Gospolitizdat (in Russian).]

Хлынов В. (2000). Общегосударственное планирование рыночной экономики: опыт Японии // Мировая экономика и международные отношения. 2000. № 8. [Khlynov V. (2000). National 
planning of a market economy: the experience of Japan. World economy and international relations, no. 8 (in Russian).]

Balassa B. (1990). Indicative planning in developing countries. Journal of Comparative Economics, vol. 14 , iss. 4 , pp. $560-574$.

Devine P. (2002). Participatory Planning through Negotiated Coordination. Science and Society, vol. 66, iss. 1, pp. 72-85.

Estrin S., Holmes P. (1983). French Planning in Theory and Practice. London: Allen \& Unwin.

Gomez-Ramirez L. (2014). On Theories of a Democratic Planned Economy and the Coevolution of "Prodemocratic Planning" Preferences. International Critical Thought, vol. 4, no. 2, pp. 178-197.

Hahnel R. (2012). Of the People, by the People: The Case for a Participatory Economy. Oakland: Soapbox Press.

Kuznets P. (1990). Indicative planning in Korea. Journal of Comparative Economics, vol. 14, iss. 4, pp. 657-676.

Laibman D. (2011). Incentive Design, Iterative Planning and Local Knowledge in a Maturing Socialist Economy. International Critical Thought, vol. 1, iss. 1, pp. 35-56.

Moriguchi Ch. (1980). Japan's Recent Experiences of Quantitative Economic Planning. Revue économique, vol. 31, no. 5, le VIII plan, pp. 853-856.

Rosser J.B., Rosser M.V. (2004). Whither indicative planning, the case of France. Comparative Economics in a Transforming World Economy, pp. 179-201.

Рукопись поступила в редакциию 29.09.2021 г.

\section{SOVIET PLANNING: WHAT AND WHY IS RELEVANT IN THE XXI CENTURY}

\author{
A.I. Kolganov
}

DOI: $10.33293 / 1609-1442-2021-4(95)-127-132$

Andrey I. Kolganov, Economic Department, Lomonosov Moscow State University; Institute of Economy, Russian
Academy of Sciences, Moscow, Russia; onaglo@mail.ru ORCID 0000-0003-2223-7538

Acknowledgments. The research was funded by RFBR, project no. 21-010-43007\21.

Planning has become widespread in countries with different socio-economic systems. At the same time, both the evaluation of the results of using planned methods and these planned methods themselves have significant differences. They depend both on the features of the socio-economic systems in which planning was applied, and on the tasks that it solved. To study these dependencies, it is useful to turn to the experience of planning in the USSR, which demonstrates different options for using planning methods. During the years of the new economic policy, planning functioned in the conditions of a broad development of market and capitalist relations. Therefore, the planning methods were adapted to the market conditions. The planning itself was mainly indicative, and the achievement of planned results was built by influencing the economic interests of economic entities. Therefore, it is possible to find a significant similarity in the model of Soviet planning during the years of the new economic policy and those planning methods that were used in the post-war period in Europe, Japan, and then in the new industrial countries. The model of directive planning, which was developed in the USSR in the 1930s of the twentieth century, provided both certain advantages in the development of the economy (the mobilization and concentration of significant masses of resources for deep structural changes in the economy, the implementation of large scientific, technical and social projects), and was burdened with serious contradictions. The Soviet model of directive planning did not have effective institutions that expressed the economic interests of enterprises and their collectives, did not create incentives for technical re-equipment of existing enterprises, and ultimately led to the predominance of the interests of the top government departments. To prevent the development of such contradictions, one-sided reflection of the interests of narrow social groups, the planned system should be built on democratic grounds.

Keywords: planning, directive planning, indicative planning, new economic policy, market economy, development, structural shifts.

JEL classification: O20, P11, P21. 